\title{
Exploring the Link Between Socially Responsible HRM and Affective Commitment of Employees in Ethiopian Context
}

\author{
Zelalem Gebretsadik Estifo* Luo Fan, Naveed Ahmad Faraz \\ School of Management, Wuhan University of Technology, Wuhan, P.R.China, 430070
}

\begin{abstract}
This investigation focuses on the impacts of socially responsible human resource management (SR-HRM) methods on affective commitment (AC) as well as the intervening impact of perceived organizational support (POS) for this association. Primary data depending on 555 respondents owned by various socially responsible companies within in Ethiopia were gathered. The data were analyzed with Partial least squares structural equation modeling (PLS-SEM) techniques using SmartPLS to determine the hypothesized connections concerning socially responsible -HRM and affective commitment.The outcomes have uncovered that the employees' perceptions of socially responsible human resource management (SR-HRM) practice impact affective commitment indirectly via perceived organizational support in Ethiopian setting. This research enhances the literature by analyzing the causal association concerning socially responsible HRM practices and employees' affective commitment in developing country context.
\end{abstract}

Keywords: Socially responsible human resource management, affective commitment, perceived organizational support.

DOI: $10.7176 / \mathrm{EJBM} / 11-9-16$

Publication date:March $31^{\text {st }} 2019$

\section{Introduction}

Committed workers are vital to strong company performance, fruitful change and, eventually, enduring corporate achievement. Enthusiasm for employee commitment has generally been driven by its implications for an organization's capacity to contend in the 'battle to get talent'(Michaels et al. 2001) and retain its most effective employees to achieve competitive advantage(Meyer 2016). Commitment is usually depicted as a critical factor that impacts the human being actions and sentiments, forms human being perceptions, and may even intervene the employee's responses to management decisions (Mercurio 2015). Even though commitment has three fundamental segments, this investigation center around affective commitment to the organization since this is a crucial component commitment towards the employer (Mercurio 2015).

Nowadays, socially responsible HRM is developing as an idea fundamentally contrived out of two zones of study, human resource management, and corporate social responsibility. These two are definitely connected since SR-HRM strategies are actually tailored to internal partners (employees) by relying on the basic principle of HRM which usually intended to advance and enhance employees welfare (Lechuga Sancho et al. 2018). It is well known that workers are definitely the foundation of all socially capable enterprise because they from the inside structure in companies, they could be liable for performing the organization activity and furthermore comprise the key component through which companies build up connections along with the several other business partners (Cantele 2018). Accordingly, whenever leaders wanted to make the strategic focus to both inward and outer partners' anticipations, desires as well as needs, they must know that obligation for an outside partner will require to handle the numerous concerns pertaining to staff members. HRM practices can be classified into three segments that are anticipated to enhance the three aspects of worker capabilities, namely skill improving, motivation-enhancing, as well as, opportunity maximizing practices (Gardner et al. 2011; Jiang et al. 2012; Lepak et al. 2006). Because affective commitment demonstrates employees' psychological connection with their organizations, it has often been considered as a representative construct of employee motivation that can be influenced by HRM systems(Meyer 2016).

In general, studies show that psychological factors, such as organizational justice, empowerment, and perceived organizational support may help to explain how HRM systems can influence affective commitment. (Chang \& Chen 2011; Van De Voorde \& Beijer 2015; Meyer 2016). Specifically, while looking at the impact of HRM frameworks on individual outcomes, researchers need to think about how employees perceive and decipher HRM systems since it is ostensibly employees' perceptions, as opposed to planned or real HRM systems, which usually impact employees' perceptions as well as, behaviors(Meyer 2016). As per these suggestions, we tend to focus the research upon the effect of socially responsible-HRM over the affective organizational commitment from employees points of view.

It is clear that earlier research interests are principally limited to the research of socially responsible HRM's effects upon facets of worker attitudes and behaviors, particularly, worker overall commitment to the organizations (Shen \& Jiuhua Zhu 2011), job satisfaction (Kundu \& Gahlawat 2015), task performance (Shen \& Benson 2016) and company citizenship behavior (Newman et al. 2016). Regardless of the previously mentioned endeavors, there 
is an absence of explicit investigation that explores the direct and indirect relationship between SRHRM and affective commitment. Further, from past investigations, it has been entrenched that CSR affects employees attitude and behavior but why, how and when is yet to be explored(Gahlawat \& Kundu 2018). Because of the high relevance of affective commitment on organizational outcomes and employee behaviors, researchers pointed out that, it is imperative to conduct studies to clearly identify those organizational practices that could help managers to uplift employees commitment to the highest level possible(Mercurio 2015).In addition, inadequate scientific studies have been done on the organizational commitment in African circumstance (Gbadamosi 2003).

Cognizant of the abovementioned gaps in research, the present study aims to examine the impact of socially responsible HRM practice on affective commitment of employees via the intervention mechanisms of perceived organizational support. Furthermore, this study also endeavors to explore the aforesaid issues in the context where it is not often studied (Ethiopia).

Cognizant of the abovementioned gaps in research, the present study aims to investigate the effect of socially responsible HRM strategies on affective commitment of workers via the intervention mechanisms of perceived organizational support. Furthermore, this research likewise tries to explore the aforesaid issues in the context where it is not often studied (Ethiopia).

\section{Conceptual background and hypotheses}

\subsection{Socially responsible HRM and affective commitment}

SRHRM is conceptualized as a group of CSR-related human resource management methods which can be directly geared towards workers and can be portrayed into three primary segments, that is, labor law-related legal compliance human resource management (LCHRM); employee-oriented human resource management (EOHRM), and general CSR facilitation human resource management (Kundu \& Gahlawat 2016). Legal compliance human resource management includes principally equity, health and safety, working hours, minimum wage and the avoidance of child labor and forced labor (Rhoades et al. 2002). Employee-oriented human resource management deals with workers' desires for personal advancement, which include training, feedback, coaching, profession, and administrative advancement as well as usage of workplace democracy, including worker involvement as well as, participation and collective decision making (Waring \& Lewer 2004). General CSR facilitation human resource management entails the use of HRM guidelines as well as , practices which usually engage companies and the staff members in general CSR endeavors including assisting community betterment (Bhattacharya et al. 2008), minimizing environmental contamination (Dixonfowler et al. 2013), fighting poverty (Jenkins 2005) and then controlling environmental destruction (Eberlein \& Matten 2009).

Affective commitment designates employees emotional attachment to and psychological identification along with the organization (Allen \& Meyer 1990). The empirical proof backs the hypothesis that an human resource management program that is likely to fulfill workers' needs is, generally, favorably associated with organizational commitment (OC), therefore confirming social attribution theory, which usually contends that workers' response for their companies rely primarily on exactly how they perceive the influence of the workplace's policies as opposed to the policies themselves (Fiske \& Taylor 1991). Different researchers have contributed to finding out the association in between socially responsible human resource management techniques and organizational commitment (Farooq et al. 2014; Brammer et al. 2007; Shen \& Jiuhua Zhu 2011). Shen \& Jiuhua Zhu have concluded that legal compliance HRM and general CSR facilitation HRM have got a positive relationship with every one of the three measurements organizational commitment (Shen \& Jiuhua Zhu 2011). Farooq et al. have attested that employee-focused CSR practices significantly impact the affective commitment of employees (Farooq et al. 2014). Likewise, Kim, Lee, Lee, \& Kim have demonstrated socially dependable exercises decidedly impact affective commitment of employees via organizational identification (Kim et al. 2010).

Moreover, if a company embraces and exercises organizational management practices consisting of organizational support and effective leadership, as well as human resource management strategies such as high commitment work policies and practices(Gill et al. 2011) the degree of its members' affective determination towards the corporation will certainly increase(Shin et al. 2017). Other than the above empirical studies, social exchange theory gives a strong foundation to relate the idea of socially responsible HRM and affective commitment in an organization set up. Cropanzano et al in his review of social exchange theory stated that "a series of successful reciprocal exchanges may transform an economic exchange relationship into a high-quality social exchange relationship" (Cropanzano et al. 2016). Along these lines, people may become affectively committed to companies (Meyer \& Allen 1997; Meyer et al. 2002). Social exchange theory anticipates the fact that pleasant commencing action ought to increase affective determination, which is a relational reciprocating response (Cropanzano et al. 2016). Depending on social exchange theory ( SET) and previously mentioned empirical review, the study suggests the subsequent hypothesis.

H1: There exists a positive association between socially responsible HRM and affective commitment 


\subsection{Socially responsible HRM and perceived organizational support}

Perceived organizational support (POS) is described as workers' perceptions regarding the magnitude that the business cherishes their contributions and cares about their particular welfare (Eisenberger et al. 1986). Signaling theory can be used as a base to argue the link between SR-HRM and POS. Signaling theory contends that workers see the company's pleasant inputs just as indicators of the help of the business which usually encourages cheerful response back to the provider (Spence 1973). A study by Pfeffer disclosed that "a number of employee-oriented CSR initiatives- such as providing life insurance, avoiding layoffs, enabling a work-life balance, providing job autonomy, and maintaining equitable remuneration-are important for maintaining the health and well-being of employees, and have positive effects on employees" (Pfeffer 2010).

Research concerning precursors of POS has consistently demonstrated that POS develops based on the receipt of favorable job conditions and rewards, the experience of personally relevant company guidelines, the experience of good treatment, as well as the relationships with agents of the organization(Eisenberger \& Stinglhamber 2011). Employees would understand the application of SRHRM particularly CSR focused towards employees in the form of LC-HRM and EO-HRM like a positive indication of positive compliment from the company. Depending on the above-mentioned justifications, the next hypothesis is proposed.

H2: There exists a significant positive correlation between socially responsible HRM and perceived organizational support.

\subsection{Perceived organizational support and affective commitment}

As per organizational support theory (Eisenberger \& Stinglhamber 2011), the formation of POS is advanced by workers' perspective of the organization like a formidable life-like being whose desirable or perhaps unfavorable positioning toward them has a bearing on how it addresses all of them (Levinson 1965). Consistent with the social exchange processes suggested by organizational support theory, high-POS workers experienced higher felt obligation targeted at company objectives, elevated affective commitment, including higher anticipation that good performance will likely be compensated(Kurtessis et al. 2017).

Concerning the outcomes of POS, research findings point out that POS increases employees' subjective wellbeing, strong inclination towards the corporation and as well, job (for example, higher affective organizational commitment and work engagement), and beneficial behaviors directed toward the company (Eisenberger \& Stinglhamber 2011). Specifically, Meyer et al.'s meta-analysis discovered that POS was the firmest determinant of affective commitment (Meyer et al. 2002). Moreover, research shows that the greater workers think supported by the corporation, the greater they will feel psychologically linked to it (Meyer 2016). Similarly, Rhoades et al. (2001) discovered that POS was in fact positively associated with changes in affective commitment over time, providing evidence that POS encourages and it is eventually a good precursor of affective determination. Dependent upon the previous pieces of facts, the third hypothesis is proposed below: H3: There exists a significant positive correlation between perceived organizational support and affective organizational commitment

\subsection{Perceived organizational support as a mediator of the relationship between socially responsible HRM and affective commitment}

Perceived organizational support has been observed to be identified with, however different from, affective commitment (Settoon et al. 1996; Rhoades et al. 2001) and, continuance commitment (Shore \& Tetrick 1991). Based on the norm of reciprocity, POS should certainly build felt accountability to pay attention to the organization's wellbeing (Eisenberger et al. 2001). The obligation to reciprocate meeting the demands of one another should boost workers' affective commitment towards the personified company (Foa \& Foa 1980). POS will typically enhance affective commitment by means of satisfying such socio-emotional desires as affiliation and psychological support (Eisenberger et al. 1986).. Similar to the causal connection between POS and affective commitment, empirical evidence has also shown that POS mediates the relationships between major antecedents of POS (that is, organizational justice, supportive supervision, and favorable job conditions) and affective commitment (Rhoades et al. 2001; Wayne et al. 1997; Shore \& Shore 1995; Stinglhamber \& Vandenberghe 2003). Relaying on the above argument, the mediation effect of POS is proposed as follows: H4. Perceived organizational support mediates the link in the relationship between socially responsible HRM and affective commitment

\section{Research methodology \\ 3.1 Sample}

The data were initially gathered from 555 non-managerial workers employed in eight local and international companies operating in Addis Ababa-Ethiopia. The data collection was deliberatively focused on companies that actively participates and noticeable in various consistent corporate social responsibility endeavors, like for example water protection endeavors, energy efficiency policies, environmentally friendly consciousness 
movements, and altruistic job inside their own local communities. The determination choice of participants in the study was done dependent on the organization's distributed social reports (through their particular web pages and through social networking and various media) and it enabled the researcher to guarantee that every partaking organization had, at a minimum, tried to develop and then put into action corporate social responsibility. This study targets CSR oriented companies because socially responsible-HRM was made using the principles attached to CSR, HRM ethics and a range of employee-oriented HRM practices.

From each of these eight socially responsible companies, just the forefront workers operating in nonmanagerial positions were chosen to be included in questionnaire distribution. Out of 1200 forms sent out on site by the investigators, with a return rate of $46 \%, 555$ functional questionnaires had been included in the research.

\subsection{Measures}

We pursued the strategies suggested by Brislin (1990) for survey translations crosswise over various dialects. To start with, the primary author who is conversant in Amharic(an official working language in Ethiopia) interpreted the English questionnaire items back into Amharic. Further, one of the article author and Ph.D. candidate in business leadership in Addis Ababa University who is capable in English and Amharic enhanced the translation by using iterative procedures in which any kind of disparity between the English and Amharic copies had been sorted out and corrected. Every one of the reactions was gone up against a five-point scale that spans from strongly disagree (lowest) to strongly agree (highest).

Predictor variable: To gauge the view of employees regarding socially responsible HRM, we utilized a 13item scales were adopted from Kundu \& Gahlawat (2016). Mediating variables: to gauge the extent of perceived organizational support, eight items were adopted from Eisenberger et al. (1986). Dependent variables: to capture the extent of employees affective commitment to the organization, we used a five-item scale adopted from Lau et al. (2017).

\section{Results}

To explore the proposed hypotheses, we applied the Partial Least Squares Structural Equation Modeling via smart PLS3- V. 3.2.7 (Ringle et al. 2015). PLS is a unique method of estimation that can handle successfully research problems and questions that require on the conceptualization, operationalization, and estimation of pure composite models, or models with a combination of composite and reflective constructs (Henseler et al. 2016). We considered this technique much more suitable as it enables to properly study variables that can be formatively modeled (Polites et al. 2012).

\subsection{Evaluation of reflectively measured constructs}

The aim of reflective measurement model assessment is usually to guarantee the reliability and validity of the construct measures and in this manner offer proof to make sure that they can be included in the model path analysis. Indication reliability, convergent validity, composite dependability, and discriminant validity are among the baseline criteria for a decision whether to include or not a certain construct in a model (Hair Jr et al. 2017)

To gauge inner consistency and reliability, Cronbach's alpha value should be greater than 0.7 , regardless of the actual fact that in exploratory studies, 0.6 is acceptable (Hair Jr et al. 2017). Composite reliability score should be greater than 0.7 (Hair Jr et al. 2016). In exploratory research, a composite reliability score of 0.60 up to 0.70 is accepted as adequate(Hair Jr et al. 2017). The indicator reliability pinpoints which aspects of the indicator's variance can be elaborated by the root latent variable (Götz et al. 2010). Indication loadings should be to the minimum 0.60 and any value higher than 0.7 is safely accepted (Henseler et al. 2016).

Convergent validity is the extent to which a measure positively relates with alternate measures of similar construct. To determine convergent validity, experts consider the external loadings of the indicators, as well as the average variance extracted (Hair Jr et al. 2017). Average variance extracted (AVE) gages the degree to which the average variance of the indicators is described by the given construct and should be above 0.5 thresholds (Fornell \& Larcker 1981).

Discriminant validity refers to the idea that each reflective construct must share more variance in relation to its own indicators than with other constructs in the model. Fornell-Larcker standard is one of the indexes you can use to measure it. The AVE of every construct must be higher than the squared correlations with all the constructs (Fornell \& Larcker 1981). Also, Cross-loadings can be utilized as a criterion to asses discriminant validity. It says that the factor loadings of every indicator variable must be higher than most of its cross-loadings (Chin 1998). Our reflective measurement model outcome exhibited in Table- $\mathbf{1}$ affirms that the indicator reliability, composite dependability, as well as convergent validity meet the cutoff requirements specified above. Table- $\mathbf{2}$ and Table-3 presents the discriminant validity evaluation results of this study which confirms that the cutoff requirements given above are fulfilled. By and large, the reflective constructs work best for PLS-SEM application given that they satisfy almost all of the cutoff benchmark outlined as a standard (Hair Jr et al. 2017). 


\subsection{Evaluation of formatively measurement construct}

To inspect constructs that are formatively modeled, the relevance and significance of the indicator weights must be evaluated, and it is important likewise to enclose the bootstrap confidence upper and lower limit that gives additional confirmation on the stability of the coefficient estimates(Hair Jr et al. 2017). Indicators' weights ought to be above 0.1 (Andreev et al. 2009) and bootstrapping ought to be utilized to check their acceptability (Hair Jr et al. 2017).

In addition, potential collinearity issues among sets of formative indicators should be tackled in the measurement model assessment. Variance inflation factor (VIF) gages the level of multicollinearity. Hair Jr et al. (2017) advised that it ought to be under five, even though Diamantopoulos \& Siguaw (2006) considered a smaller threshold of 3.3. Table- 4 presents the output of assessing our formatively measured construct (socially responsible HRM). All of the above-mentioned cutoff criteria's are satisfied. By accounting for the above-mentioned issues, one makes sure that the formative construct can be used for the PLS-SEM analysis and that the estimations of outer weights are correctly interpreted (Hair Jr et al. 2017).

\subsection{Evaluation of structural model}

In the first stage when one begin assessing the PLS-SEM outcome for the structural equation model, the main issues to analyze are the relevance and significance of the indicators. Examining the significance calls for the usage of the bootstrapping techniques and proper scrutiny(analysis) of the $t$ and $p$ values, as well as bootstrapping confidence upper and lower limits (Hair Jr et al. 2017). Table -5 presents the final outcomes of our study. In the relationship between SRHRM to affective commitment (AC), the confidence interval (CI) contains zero and the beta coefficient and the $t$-value is beneath the cutoff point. $(\beta=0.097 ; \mathrm{t}=1.6298$; lower $\mathrm{CI}=-0.0182$, Upper CI $=0.2118)$, therefore the direct effect of SR-HRM on AC $\left(\mathrm{H}_{1}\right)$ is not supported. With regard to the second hypotheses (SRHRM $\rightarrow$ POS), the confidence interval $(\mathrm{CI})$ did not contain a zero and the beta coefficient and the $\mathrm{t}$-value is above the cutoff point $(\beta=0.618$; $\mathrm{t}=16.599$; lower $\mathrm{CI}=0.5435$; Upper $\mathrm{CI}=0.6787)$, as a result, $\mathrm{H}_{2}$ is supported.

Similarly, in the third hypothesis (POS $\rightarrow \mathrm{AC}$ ), the confidence interval $(\mathrm{CI})$ did not contain a zero and the beta coefficient and the $t$-value is above the cutoff point $(\beta=0.439$; $t=8.596$; lower $C I=0.3281$; Upper $C I=0.5364)$, as a result, $\mathrm{H}_{3}$ is supported. In case of indirect path, i.e. mediation through perceived organizational support, the confidence interval (CI) did not contain a zero and the beta coefficient and the t-value is above the cutoff point $(\beta=0.116 ; t=6.988$; lower $\mathrm{CI}=0.0835$, Upper $\mathrm{CI}=0.1490)$, hence $\mathrm{H}_{4}(\mathrm{SRHRM} \rightarrow \mathrm{POS} \rightarrow \mathrm{AOC})$ is supported. A complete (full) mediation is usually portrayed in the case in which the direct effect(c') is definitely not significant, in contrast, the indirect effect (a x b) is definitely significant (Latan \& Noonan 2017).In our case, the direct effect(SRHRM $\rightarrow$ AC) is not significant $(\beta=0.097 ; \mathrm{t}=1.629$; lower $\mathrm{CI}=-0.0182$, Upper CI 0.2118), whereas the indirect effects are significant $(\mathrm{SRHRM} \rightarrow \mathrm{POS}$; and $\mathrm{POS} \rightarrow \mathrm{AC}$ ) as a result we conclude that there is a full mediation.

Next, we evaluated the coefficients of determination, predictive relevance, and effect size in order to get insight into how much the exogenous construct impacts the endogenous ones. Coefficients of determination $\left(\mathrm{R}^{2}\right)$ captures the extent of explained variance of the dependent variables in the model(Hair Jr et al. 2017). Our model explains 26 and 38 percent of the changes in AC, and POS, respectively(Table- 6). According to Cohen (1988), our model's coefficients of determination values for the endogenous constructs can be categorized as a large effect. The $\mathrm{f}^{2}$ effect size helps us to analyze the importance of predictors in explaining a given dependent construct. particularly, we investigated the extent to which the predictor construct adds to the $\mathrm{R}^{2}$ value of a dependent construct in the model. outcomes of $0.02,0.15$, and 0.35 are deciphered as a small, medium, and large $\mathrm{f}^{2}$ effect sizes, correspondingly(Hair Jr et al. 2017). Table- 5 depicts the effect size regarding the exogenous constructs effect size on endogenous constructs. SRHRM has large effect size on POS whereas POS has a medium effect size on affective commitment. Further, we applied the blindfolding techniques for measuring the predictive relevance $\left(\mathrm{Q}^{2}\right)$ of the path model. A given path model for a reflective endogenous construct will be rated as having a predictive relevance as far as its $\mathrm{Q}^{2}$ value is greater than zero (Hair Jr et al. 2016) The information in Table- 6 proves that our model has predictive relevance.

\section{Discussion}

This study has revolved around employee centered corporate social responsibility (CSR) practices mainly, alluded them as socially responsible HRM strategies and has studied their particular effect on the affective commitment of employees. Depending on the data gathered from 555 employees out of eight different companies working in Ethiopia, this research has particularly addressed the recent call of Mercurio (2015) to investigate organizational interventions and practices that could uplift affective commitment of employees. Furthermore, this study outcomes answers the call for research to analyze whether the socially responsible policies affect the commitment level of employees (Barrena-Martinez et al. 2017).

The outcomes, in primary, shows that adherence of organizations to socially responsible practices like 
provision of equal opportunities in HRM, conformity with the labor laws and regulations, appointing staff to apply general CSR activities, taking initiatives that help in poverty reduction and environmental protection contributes to a supportive workplace and high reliable relationships between workers and management, which, subsequently, positively influence the quality of employees' perceived organizational support. Furthermore, perceived organizational support foresters workers' affective commitment. In agreement with the present outcomes, previous studies have shown that POS predicts organizational commitment (Loi et al. 2006).

Contrary to anticipations, this study didn't get a significant direct link between socially responsible HRM and affective commitment. Dissenting from the outcomes of this study, a prior investigation has found that the relationship between socially responsible HRM and commitment is direct(Shen \& Jiuhua Zhu 2011). On the other hand, this study confirms a strong and full mediation of perceived organizational support in the relationship between SR-HRM and affective commitment. The findings of the current study are consistent with those of Shen \& Benson (2016) who advised organizations to provide considerable organizational support through identifying the nature of and attempting to meet, employees' issues, which allows the positive effects of CSR and socially responsible HRM on employee work behaviors to be realized.

\section{Practical implications}

The findings of the socially responsible HRM practice-affective commitment relationship offer imperative implications for organizations aimed at enhancing employees' affective commitment. To be able to foster affective commitment, organizations should excel in socially responsible HRM practice. Special emphasis ought to be directed at employee-oriented HRM practice such as for example providing sufficient training and advancement opportunities to employees to be able to indicate that companies really are concerned about their personal development and growth. Furthermore, practicing managers have to pay high interest to the essential legal rights of workers, which match the financial and legal obligations regarding workers. Workplace safety and health, protecting employees from layoff, fair promotions, and wages, work-life stability, and labor union representation is among the critical areas that require managers attention (Turker 2018).

The study also highlights the need for fulfilling ethical responsibilities in handling diversity, supporting workers to develop their unique career path, rendering further training, college education, and making sure the application of important principles such as for instance justice, integrity in each and every worker-related concern (Turker 2018). Ethical duties could be important in the aspects of developing reasonable and dependable overall performance evaluation and reward mechanism. Guaranteeing complete overall justice is crucial for workers and companies that would like to engender efficiency, effectiveness, citizenship behavior, dedication and loyalty(Cohen-Charash \& Spector 2001)

Overall, this study fortifies the idea that companies should properly shoulder their philanthropic responsibilities towards employees and even the local community. Gratifying this obligation basically involves building their social responsibility to staff members out of a paternalistic point of view and care and handling employees, their loved ones by designing an appropriate child or elderly care and attention centers, pension schemes, internship intended for youth, workers voluntarism, and charity activity (Turker 2018).

\section{Limitations and future research directions}

The data utilized in our investigation were gathered through self-report measures, which may bring up issues of common method bias. Be that as it may, our interest in workers' perceptions made self-report measures suitable for the current research (Levin \& Cross 2004). Preventive measures like guaranteeing response secrecy and then assuring participants the fact that there have been no correct responses to the inquiries could decrease the danger of common- method variance (Podsakoff et al. 2003). We applied the above-mentioned intervention with the aim to limit the effect of method bias in our research. Possible future study will take advantage of investigating HRM systems from both employees' and managers' perspectives(Liao et al. 2009). Moreover, the cross-sectional type of research can certainly be seen as a limitation. A longitudinal study configuration will be much more unbiased and reliable and offers information and facts regarding probable changes in affective commitment level over time and this can be another road for further study.

\section{References}

Allen, N.J. \& Meyer, J.P., 1990. The measurement and antecedents of affective, continuance and normative commitment to the organization. Journal of occupational psychology, 63(1), pp.1-18.

Andreev, P. et al., 2009. Validating formative partial least squares (PLS) models: methodological review and empirical illustration. ICIS 2009 Proceedings, p.193.

Barrena-Martinez, J., López-Fernández, M. \& Romero-Fernández, P.M., 2017. Socially responsible human resource policies and practices: Academic and professional validation. European Research on Management and Business Economics, 23(1), pp.55-61.

Bhattacharya, C.B., Sen, S. \& Korschun, D., 2008. Using Corporate Social Responsibility to Win the War for 
Talent. MIT Sloan Management Review, 49(1), pp.37-43.

Brammer, S., Millington, A. \& Rayton, B., 2007. The contribution of corporate social responsibility to organizational commitment. The International Journal of Human Resource Management, 18(10), pp.17011719.

Brislin, R.W., 1990. Applied cross-cultural psychology, Sage Publications.

Cantele, S., 2018. Human resources management in responsible small businesses: why, how and for what? International Journal of Human Resources Development and Management, 18(1-2), pp.112-126.

Chang, P.-C. \& Chen, S.-J., 2011. Crossing the level of employee's performance: HPWS, affective commitment, human capital, and employee job performance in professional service organizations. The international journal of human resource management, 22(04), pp.883-901.

Chin, W.W., 1998. The partial least squares approach to structural equation modeling. Modern methods for business research, 295(2), pp.295-336.

Cohen, J., 1988. Statistical power analysis for the behavioral sciences 2nd edn.

Cohen-Charash, Y. \& Spector, P.E., 2001. The role of justice in organizations: A meta-analysis. Organizational behavior and human decision processes, 86(2), pp.278-321.

Cropanzano, R. et al., 2016. Social exchange theory: A critical review with theoretical remedies. Academy of Management Annals, pp.1-107.

Van De Voorde, K. \& Beijer, S., 2015. The role of employee HR attributions in the relationship between highperformance work systems and employee outcomes. Human Resource Management Journal, 25(1), pp.6278.

Diamantopoulos, A. \& Siguaw, J.A., 2006. Formative versus reflective indicators in organizational measure development: A comparison and empirical illustration. British Journal of Management, 17(4), pp.263-282.

Dixonfowler, H.R. et al., 2013. Beyond “Does it Pay to be Green?” A Meta-Analysis of Moderators of the CEPCFP Relationship. Journal of Business Ethics, 112(2), pp.353-366.

Eberlein, B. \& Matten, D., 2009. Business Responses to Climate Change Regulation in Canada and Germany: Lessons for MNCs from Emerging Economies. Journal of Business Ethics, 86(2), pp.241-255.

Eisenberger, R. et al., 1986. Perceived organizational support. Journal of Applied Psychology, 71(3), pp.500-507.

Eisenberger, R. et al., 2001. Reciprocation of perceived organizational support. Journal of applied psychology, $86(1), \mathrm{p} .42$.

Eisenberger, R. \& Stinglhamber, F., 2011. Perceived organizational support: Fostering enthusiastic and productive employees., American Psychological Association.

Farooq, O. et al., 2014. The impact of corporate social responsibility on organizational commitment: Exploring multiple mediation mechanisms. Journal of Business Ethics, 125(4), pp.563-580.

Fiske, S. \& Taylor, S., 1991. Social Cognition (McGraw Hill, New York) Google Scholar.

Foa, E.B. \& Foa, U.G., 1980. Resource theory, Springer.

Fornell, C. \& Larcker, D.F., 1981. Structural equation models with unobservable variables and measurement error: Algebra and statistics. Journal of marketing research, pp.382-388.

Gahlawat, N. \& Kundu, S.C., 2018. Exploring the connection between socially responsible HRM and citizenship behavior of employees in Indian context. Journal of Indian Business Research.

Gardner, T.M., Wright, P.M. \& Moynihan, L.M., 2011. The impact of motivation, empowerment, and skillenhancing practices on aggregate voluntary turnover: The mediating effect of collective affective commitment. Personnel psychology, 64(2), pp.315-350.

Gbadamosi, G., 2003. HRM and the commitment rhetoric: challenges for Africa. Management Decision, 41(3), pp.274-280.

Gill, H. et al., 2011. Affective and continuance commitment and their relations with deviant workplace behaviors in Korea. Asia Pacific Journal of Management, 28(3), pp.595-607.

Götz, O., Liehr-Gobbers, K. \& Krafft, M., 2010. Evaluation of structural equation models using the partial least squares (PLS) approach. In Handbook of partial least squares. Springer, pp. 691-711.

Hair Jr, J.F. et al., 2017. A primer on partial least squares structural equation modeling (PLS-SEM), Sage Publications.

Hair Jr, J.F. et al., 2016. A primer on partial least squares structural equation modeling (PLS-SEM), Sage Publications.

Henseler, J., Hubona, G. \& Ray, P.A., 2016. Using PLS path modeling in new technology research: updated guidelines. Industrial management $\mid \&$ data systems, 116(1), pp.2-20.

Jenkins, R., 2005. Globalization, Corporate Social Responsibility and poverty. International Affairs, 81(3), pp. 525-540.

Jiang, K. et al., 2012. Clarifying the construct of human resource systems: Relating human resource management to employee performance. Human resource management review, 22(2), pp.73-85.

Kim, H.-R. et al., 2010. Corporate social responsibility and employee-company identification. Journal of Business 
Ethics, 95(4), pp.557-569.

Kundu, S.C. \& Gahlawat, N., 2016. Effects of socially responsible HR practices on employees' work attitudes. International Journal of Human Resources Development and Management, 16(3-4), pp.140-160.

Kundu, S.C. \& Gahlawat, N., 2015. Socially responsible HR practices and employees' intention to quit: The mediating role of job satisfaction. Human Resource Development International, 18(4), pp.387-406.

Kurtessis, J.N. et al., 2017. Perceived organizational support: A meta-analytic evaluation of organizational support theory. Journal of Management, 43(6), pp.1854-1884.

Latan, H. \& Noonan, R., 2017. Partial least squares path modeling: basic concepts, methodological issues and applications, Springer.

Lau, P.Y.Y. et al., 2017. Ethical work climate, employee commitment and proactive customer service performance: Test of the mediating effects of organizational politics. Journal of Retailing and Consumer Services, 35, pp.20-26.

Lechuga Sancho, M.P. et al., 2018. Understanding the link between socially responsible human resource management and competitive performance in SMEs. Personnel Review, 47(6), pp.1211-1243.

Lepak, D.P. et al., 2006. A conceptual review of human resource management systems in strategic human resource management research. In Research in personnel and human resources management. Emerald Group Publishing Limited, pp. 217-271.

Levin, D.Z. \& Cross, R., 2004. The strength of weak ties you can trust: The mediating role of trust in effective knowledge transfer. Management science, 50(11), pp.1477-1490.

Levinson, H., 1965. Reciprocation: The Relationship Between Man and Organization. Administrative Science Quarterly, 9(4), p.370.

Liao, H. et al., 2009. Do they see eye to eye? Management and employee perspectives of high-performance work systems and influence processes on service quality. Journal of applied psychology, 94(2), p.371.

Loi, R., Hang-Yue, N. \& Foley, S., 2006. Linking employees' justice perceptions to organizational commitment and intention to leave: The mediating role of perceived organizational support. Journal of Occupational and Organizational Psychology, 79(1), pp.101-120.

Mercurio, Z.A., 2015. Affective commitment as a core essence of organizational commitment: an integrative literature review. Human Resource Development Review, 14(4), pp.389-414.

Meyer, J.P. et al., 2002. Affective, continuance, and normative commitment to the organization: A meta-analysis of antecedents, correlates, and consequences. Journal of vocational behavior, 61(1), pp.20-52.

Meyer, J.P., 2016. Handbook of employee commitment, Edward Elgar Publishing.

Meyer, J.P. \& Allen, N.J., 1997. Commitment in the workplace: Theory, research, and application, Sage.

Michaels, E., Handfield-Jones, H. \& Axelrod, B., 2001. The war for talent, Harvard Business Press.

Newman, A. et al., 2016. The impact of socially responsible human resource management on employees' organizational citizenship behaviour: the mediating role of organizational identification. The International Journal of Human Resource Management, 27(4), pp.440-455.

Pfeffer, J., 2010. Building Sustainable Organizations: The Human Factor. Academy of Management Perspectives, 24(1), pp.34-45.

Podsakoff, P.M. et al., 2003. Common method biases in behavioral research: a critical review of the literature and recommended remedies. Journal of applied psychology, 88(5), p.879.

Polites, G.L., Roberts, N. \& Thatcher, J., 2012. Conceptualizing models using multidimensional constructs: a review and guidelines for their use. European Journal of Information Systems, 21(1), pp.22-48.

Rhoades, L., Eisenberger, R. \& Armeli, S., 2001. Affective commitment to the organization: The contribution of perceived organizational support. Journal of applied psychology, 86(5), p.825.

Rhoades, L., Eisenberger, R. \& others, 2002. Perceived organizational support: A review of the literature. Journal of applied psychology, 87(4), pp.698-714.

Ringle, C., Wende, S. \& Becker, J., 2015. SmartPLS 3 (http://www. smartpls. com), SmartPLS GmbH.

Settoon, R.P., Bennett, N. \& Liden, R.C., 1996. Social exchange in organizations: Perceived organizational support, leader-member exchange, and employee reciprocity. Journal of applied psychology, 81(3), p.219.

Shen, J. \& Benson, J., 2016. When CSR is a social norm: How socially responsible human resource management affects employee work behavior. Journal of Management, 42(6), pp.1723-1746.

Shen, J. \& Jiuhua Zhu, C., 2011. Effects of socially responsible human resource management on employee organizational commitment. The International Journal of Human Resource Management, 22(15), pp.3020 3035 .

Shin, I. et al., 2017. Hidden Roles of CSR: Perceived Corporate Social Responsibility as a Preventive against Counterproductive Work Behaviors. Sustainability, 9(955), pp.1-12. Available at: http://www.mdpi.com/2071-1050/9/6/955.

Shore, L.M. \& Shore, T.H., 1995. Perceived organizational support and organizational justice. Organizational politics, justice, and support: Managing the social climate of the workplace, 149, p.164. 
Shore, L.M. \& Tetrick, L.E., 1991. A construct validity study of the survey of perceived organizational support. Journal of Applied Psychology, pp.637-643.

Spence, M., 1973. Job market signaling. The quarterly journal of Economics, 87(3), pp.355-374.

Stinglhamber, F. \& Vandenberghe, C., 2003. Organizations and supervisors as sources of support and targets of commitment: A longitudinal study. Journal of Organizational Behavior: The International Journal of Industrial, Occupational and Organizational Psychology and Behavior, 24(3), pp.251-270.

Turker, D., 2018. Social Responsibility and Human Resource Management. In Managing Social Responsibility. Springer, pp. 131-144.

Waring, P. \& Lewer, J., 2004. The Impact of Socially Responsible Investment on Human Resource Management: A Conceptual Framework. Journal of Business Ethics, 52(1), pp.99-108.

Wayne, S.J., Shore, L.M. \& Liden, R.C., 1997. Perceived organizational support and leader-member exchange: A social exchange perspective. Academy of Management journal, 40(1), pp.82-111.

\section{Appendix: Tables and Figures}

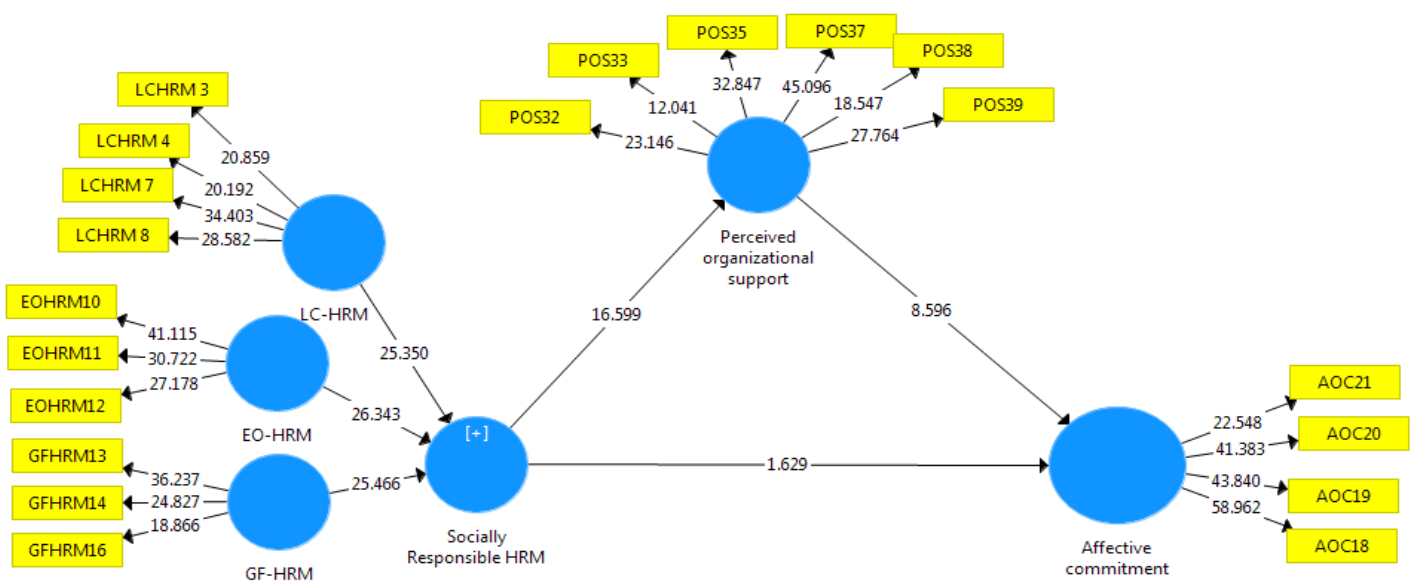

Figure 1: PLS-path analysis of bootstrapping $(n=555)$

Table 1: Results summary for reflective outer model

\begin{tabular}{|c|c|c|c|c|c|}
\hline \multirow{2}{*}{$\begin{array}{l}\text { Latent } \\
\text { variable }\end{array}$} & \multirow[t]{2}{*}{ Indicator } & $\begin{array}{c}\text { Outer } \\
\text { loading }\end{array}$ & AVE & $\begin{array}{l}\text { Composite } \\
\text { Reliability }\end{array}$ & $\begin{array}{c}\text { Cronbach's } \\
\text { Alpha }\end{array}$ \\
\hline & & $>0.70$ & $>0.50$ & $0.60-0.09$ & $0.60-0.09$ \\
\hline \multirow{4}{*}{ LC- HRM } & LCHRM 3 & 0.719 & \multirow{4}{*}{0.5280} & \multirow{4}{*}{0.818} & \multirow{4}{*}{0.703} \\
\hline & LCHRM 4 & 0.696 & & & \\
\hline & LCHRM 7 & 0.753 & & & \\
\hline & LCHRM 8 & 0.738 & & & \\
\hline \multirow{3}{*}{ EO-HRM } & EOHRM10 & 0.778 & \multirow{3}{*}{0.583} & \multirow{3}{*}{0.808} & \multirow{3}{*}{0.676} \\
\hline & EOHRM11 & 0.712 & & & \\
\hline & EOHRM12 & 0.701 & & & \\
\hline \multirow{3}{*}{ GF-HRM } & GFHRM13 & 0.787 & \multirow{3}{*}{0.545} & \multirow{3}{*}{0.782} & \multirow{3}{*}{0.585} \\
\hline & GFHRM14 & 0.726 & & & \\
\hline & GFHRM16 & 0.699 & & & \\
\hline \multirow{4}{*}{$\mathbf{A C}$} & AOC18 & 0.875 & \multirow{4}{*}{0.690} & \multirow{4}{*}{0.898} & \multirow{4}{*}{0.848} \\
\hline & AOC19 & 0.868 & & & \\
\hline & AOC20 & 0.851 & & & \\
\hline & $\mathrm{AOC} 21$ & 0.718 & & & \\
\hline \multirow{6}{*}{ POS } & POS32 & 0.702 & \multirow{6}{*}{0.509} & \multirow{6}{*}{0.860} & \multirow{6}{*}{0.805} \\
\hline & POS33 & 0.570 & & & \\
\hline & POS35 & 0.759 & & & \\
\hline & POS37 & 0.810 & & & \\
\hline & POS38 & 0.676 & & & \\
\hline & POS39 & 0.742 & & & \\
\hline
\end{tabular}


Table 2: Fornell-Larcker criterion analysis for checking discriminant validity

\begin{tabular}{lccccc}
\hline Latent variable & AC & EO -HRM & GF- HRM & LC- HRM & POS \\
\hline Affective commitment & $\mathbf{0 . 8 3 1}$ & & & & \\
Employee oriented -HRM & 0.320 & $\mathbf{0 . 7 6 4}$ & & & \\
General facilitation HRM & 0.259 & 0.608 & $\mathbf{0 . 7 3 8}$ & & \\
Legal compliance HRM & 0.360 & 0.624 & 0.517 & $\mathbf{0 . 7 2 7}$ & $\mathbf{0 . 7 1 4}$ \\
Perceived organizational support & 0.499 & 0.529 & 0.472 & 0.554 & $\mathbf{0}$ \\
\hline
\end{tabular}

*Note: Diagonal row presents the square root of the AVE.

Table 3: Discriminant Validity based on Cross-loading Evaluation

\begin{tabular}{lccccc}
\hline & AOC & EO-HRM & GF-HRM & LC-HRM & POS \\
\hline AOC18 & $\mathbf{0 . 8 7 6}$ & 0.273 & 0.166 & 0.311 & 0.396 \\
AOC19 & $\mathbf{0 . 8 6 8}$ & 0.231 & 0.206 & 0.271 & 0.390 \\
AOC20 & $\mathbf{0 . 8 5 1}$ & 0.236 & 0.207 & 0.287 & 0.425 \\
AOC21 & $\mathbf{0 . 7 1 8}$ & 0.310 & 0.266 & 0.308 & 0.432 \\
EOHRM10 & 0.277 & $\mathbf{0 . 7 8 5}$ & 0.509 & 0.531 & 0.473 \\
EOHRM11 & 0.255 & $\mathbf{0 . 7 7 4}$ & 0.433 & 0.464 & 0.360 \\
EOHRM12 & 0.196 & $\mathbf{0 . 7 3 1}$ & 0.447 & 0.420 & 0.371 \\
GFHRM13 & 0.261 & 0.525 & $\mathbf{0 . 7 8 4}$ & 0.471 & 0.419 \\
GFHRM14 & 0.131 & 0.425 & $\mathbf{0 . 7 3 2}$ & 0.271 & 0.334 \\
GFHRM16 & 0.167 & 0.384 & $\mathbf{0 . 6 9 8}$ & 0.382 & 0.281 \\
LCHRM 3 & 0.318 & 0.518 & 0.397 & $\mathbf{0 . 7 1 6}$ & 0.473 \\
LCHRM 4 & 0.210 & 0.403 & 0.283 & $\mathbf{0 . 6 9 4}$ & 0.375 \\
LCHRM 7 & 0.278 & 0.469 & 0.394 & $\mathbf{0 . 7 5 6}$ & 0.382 \\
LCHRM 8 & 0.234 & 0.418 & 0.414 & $\mathbf{0 . 7 4 0}$ & 0.377 \\
POS32 & 0.379 & 0.400 & 0.331 & 0.408 & $\mathbf{0 . 7 0 1}$ \\
POS33 & 0.347 & 0.255 & 0.164 & 0.260 & $\mathbf{0 . 5 7 1}$ \\
POS35 & 0.314 & 0.401 & 0.362 & 0.459 & $\mathbf{0 . 7 5 8}$ \\
POS37 & 0.352 & 0.456 & 0.460 & 0.450 & $\mathbf{0 . 8 0 9}$ \\
POS38 & 0.399 & 0.304 & 0.279 & 0.326 & $\mathbf{0 . 6 7 7}$ \\
POS39 & 0.362 & 0.415 & 0.374 & 0.419 & $\mathbf{0 . 7 4 3}$ \\
\hline
\end{tabular}

Table 4: Measurement Model Evaluation: Composite model (composite construct)

\begin{tabular}{llllcccc}
\hline $\begin{array}{c}\text { Formative } \\
\text { construct }\end{array}$ & $\begin{array}{c}\text { Formative } \\
\text { indicators }\end{array}$ & Indicators & VIF & $\begin{array}{c}\text { Outer } \\
\text { weights }\end{array}$ & $\begin{array}{c}\text { 95\% BCa confidence } \\
\text { interval }\end{array}$ & $\begin{array}{c}\text { Outer } \\
\text { loading }\end{array}$ \\
\hline SRHRM & & LCHRM 3 & 1.4060 & 0.3696 & 0.3407 & 0.4025 & 0.74870 \\
& \multirow{2}{*}{ LC- HRM } & LCHRM 4 & 1.2870 & 0.3103 & 0.2745 & 0.3431 & 0.70360 \\
& & LCHRM 7 & 1.3830 & 0.3496 & 0.3189 & 0.3833 & 0.73640 \\
& LCHRM 8 & 1.3550 & 0.3440 & 0.3126 & 0.3784 & 0.71940 \\
& \multirow{2}{*}{ EO-HRM } & EOHRM10 & 1.2640 & 0.3960 & 0.3683 & 0.4290 & 0.77920 \\
& & EOHRM11 & 1.2940 & 0.3504 & 0.3223 & 0.3792 & 0.71240 \\
& EOHRM12 & 1.2260 & 0.3389 & 0.3110 & 0.3701 & 0.70000 \\
& GF-HRM & GFHRM13 & 1.1960 & 0.5275 & 0.4844 & 0.5847 & 0.79280 \\
& & GFHRM14 & 1.2130 & 0.3982 & 0.3548 & 0.4405 & 0.71890 \\
& GFHRM16 & 1.2660 & 0.4224 & 0.3749 & 0.4681 & 0.69970 \\
\hline
\end{tabular}

*Note: BCa stands for bias-corrected and accelerated 
Table 5: The summary results of hypothesis testing

\begin{tabular}{lccccc}
\hline Hypothesis & $\begin{array}{l}\text { Beta } \\
\text { coefficient }\end{array}$ & $\begin{array}{l}\text { t- } \\
\text { value }\end{array}$ & $\begin{array}{c}\text { Bias-Corrected } \\
\text { Confidence } \\
\text { Interval }\end{array}$ & F2 & Inferences \\
\hline & \multicolumn{5}{c}{ Direct effects } \\
\hline SRHRM $\rightarrow$ AC(H1) & 0.097 & 1.629 & {$[-0.0182-0.2118]$} & 0.0107 & Not Supported \\
$\mathrm{SRHRM} \rightarrow \mathrm{POS}(\mathrm{H} 2)$ & 0.618 & 16.599 & {$[0.5435-0.6787]$} & 0.6359 & Supported \\
$\mathrm{POS} \rightarrow \mathrm{AC}(\mathrm{H} 3)$ & 0.439 & 8.596 & {$[0.3281-0.5364]$} & 0.1655 & Supported \\
\hline & \multicolumn{7}{c}{ Indirect effect } & Supported(full \\
\hline $\mathrm{SRHRM} \rightarrow \mathrm{POS} \rightarrow \mathrm{AC}(\mathrm{H} 4)$ & 0.116 & 6.988 & {$[0.0835-0.1490]$} & mediation) \\
\hline
\end{tabular}

Table 6. Predictive relevance and coefficient of determination

\begin{tabular}{lcccc}
\hline Latent variable & SSO & SSE & $\mathbf{Q}^{\mathbf{2}}$ (=1-SSE/SSO) & $\mathbf{R}^{\mathbf{2}}$ \\
\hline Affective commitment & $2,220.00$ & $1,863.65$ & 0.1605 & 0.2603 \\
Perceived organizational support & $3,330.00$ & $2,725.31$ & 0.1816 & 0.3858 \\
Socially Responsible HRM Practice & $6,105.00$ & $3,899.62$ & 0.3612 & \\
\hline
\end{tabular}

